\title{
Developmental Outcomes of Very Low Birth Weight Infants with Catch-up Head Growth: A Nationwide Cohort Study
}

\section{You Mi Hong}

Jeonbuk National University

Dong Hue Cho

Jeonbuk National University

Jin Kyu Kim ( $\square$ Kyunim99@gmail.com )

Jeonbuk National University

\section{Research Article}

Keywords: Korean Neonatal Network (KNN), very low birth weight (VLBW), necrotizing enterocolitis (NEC), bronchopulmonary dysplasia (BPD)

Posted Date: October 7th, 2021

DOl: https://doi.org/10.21203/rs.3.rs-945824/v1

License: (c) (1) This work is licensed under a Creative Commons Attribution 4.0 International License. Read Full License 


\section{Abstract}

This study aims to determine demographic or perinatal characteristics in premature infant according to head growth, identify clinical factors affecting growth catch-up, and find differences in developmental outcomes according to catch-up states based on Korean Neonatal Network (KNN) data. This nationwide prospective cohort study of Korean Neonatal Network (KNN) data analyzed premature infants with very low birth weight $(<1,500 \mathrm{~g})$ between 2014 and 2017. A total of 253 eligible infants who had completed Bayley scales of infant and toddler development (BSID) $3^{\text {rd }}$ were assigned into two groups: a catch-up (CU) group with head circumference above the $10^{\text {th }}$ percentile and a no catch-up (NCU) group with head circumference below the $10^{\text {th }}$ percentile at $18-24$ months of corrected age (CA). Most $(81.4 \%, 203 / 253)$ premature infants exhibited catch-up growth at 18-24 months of CA. Rates of microcephaly, intraventricular hemorrhage (IVH), bronchopulmonary dysplasia (BPD), sepsis, necrotizing enterocolitis (NEC), length of NICU stay, ventilation care, and parenteral nutrition were significantly greater in the NCU group $(P<0.05)$. On multiple linear regression analysis, the BPD status was the most clinical factor affecting catch-up head growth after adjusting for gestational age, birth weight, and birth head circumference (adjusted OR 4.586, 95\% Cl 1.960-10.729)

At 18-24 months of CA, the NCU group exhibited lower developmental indices and higher rate of developmental delay than the CU group. Motor developmental delay was the most significant factor relevant to catch-up head growth and the motor development index difference between the two groups was only statistically significant after adjusting for four major neonatal morbidities: IVH, BPD, sepsis, and NEC status (adjusted OR 10.727, 95\% Cl 1.922-59.868). Thus, the developmental outcome of very low birth weight (VLBW) infants at 18-24 months of CA might be dependent on whether head growth was caught up. Key clinical factors determining the catch-up status were BPD and NEC status, length of parenteral nutrition, and ventilator care. Thus, measurements of head circumference at 18-24 months of CA can predict developmental delays of VLBW infants.

\section{Introduction}

Recent advances in neonatal and neonatal intensive care have improved infant survival rates. In Korea, the survival rate of very low birth weight (VLBW) infants has also increased from $34 \%$ in the 1960 s to $77.5 \%$ in the $2000 \mathrm{~s}^{1}$. However, VLBW still remains a major cause of infant mortality and morbidity. For this reason, there are concerns that the improved survival of infants with VLBW might be accompanied by increases of disabling morbidity in survivors ${ }^{2,3,4}$. While the incidence of severe cerebral palsy, blindness, and hearing impairment have decreased over time, cognitive impairments have become more prevalent sequelae in VLBW children ${ }^{5}$. Although premature birth in itself might adversely affect later development, insight into factors influencing cognitive outcomes is key to improving such outcomes. However, few studies have reported the correlation between developmental outcome and head growth in VLBW infants. The Korean Neonatal Network (KNN) is a nationwide, multicenter, prospective, web-based cohort registry system for VLBW infants with a birth weight less than 1,500 g. This study aims to determine demographic or perinatal characteristics in premature infant according to head growth, identify clinical factors affecting 
growth catch-up, and find differences in developmental outcomes according to catch-up states based on KNN cohort data.

\section{Results}

\section{Distribution of 18-24 months of corrected age (CA) and three growth parameters of VLBW infants}

Head circumference, body weight, and height growth states at 18-24 months of CA are shown in Table 1. Most $(81.4 \%, 206 / 253)$ VLBW infants caught up their head growths at 18-24 months of CA. Infants in the no catch-up (NCU) group had smaller head circumferences, shorter heights, and less body weights than those in the catch-up (CU) group (head circumference: $44.6 \mathrm{~cm}$ vs. $47.2 \mathrm{~cm}$; height: $81.0 \mathrm{~cm}$. vs. $83.8 \mathrm{~cm}$; body weight: $9.7 \mathrm{~kg}$ vs. $11.2 \mathrm{~kg})$. These differences were all statistically significant $(P<0.001)$. Among the three parameters (head circumference, body weight, and height growth), head circumference had the biggest difference between the two groups. It decreased from birth to discharge. However, it increased from discharge to $18-24$ months of CA $(1.6 \mathrm{~cm}, 0.4 \mathrm{~cm}$, and $2.6 \mathrm{~cm}$ at birth, discharge, and $18-24$ months of CA, respectively) (Appendix 1).

Table 1. Distribution of 18-24 month of CA catch-up status and three growth parameters in VLBW infants

\begin{tabular}{lllllll} 
& $\mathrm{CU}$ & \multicolumn{2}{c}{$\mathrm{NCU}$} & \multicolumn{2}{c}{ Total } & \\
\cline { 2 - 6 } & $\mathrm{N}(\%)$ & $\mathrm{M} \pm \mathrm{SD}$ & $\mathrm{N}(\%)$ & $\mathrm{M} \pm \mathrm{SD}$ & $\mathrm{M} \pm \mathrm{SD}(\mathrm{cm})$ & $P$ value \\
\cline { 1 - 5 } $\mathrm{HC}$ & $206(81.4)$ & $47.2 \pm 3.5$ & $47(18.6)$ & $44.6 \pm 1.0$ & $46.7 \pm 3.4$ & $<0.001^{\star \star \star}$ \\
\hline HT & & $83.8 \pm 4.1$ & & $81.0 \pm 3.5$ & $83.3 \pm 4.2$ & $<0.001^{\star \star \star}$ \\
\hline WT & $11.2 \pm 1.4$ & & $9.7 \pm 1.0$ & $10.9 \pm 1.4$ & $<0.001^{\star \star \star}$
\end{tabular}

Abbreviations: CA, Corrected age; CU, Catch-up group; HC, Head circumference; HT, Height; $\mathrm{M} \pm \mathrm{SD}$, Mean \pm Standard deviations; NCU, No catch-up group; WT, Weight $\star \star \star P<0.001$ compared with $\mathrm{CU}$

By independent T-test

\section{Comparison of demographic and perinatal characteristics between CU and NCU groups of VLBW infants}

Demographic and perinatal characteristics of VLBW infants according to catch-up status are shown in Table 2. Rates of microcephaly, intraventricular hemorrhage (IVH), bronchopulmonary dysplasia (BPD), sepsis, necrotizing enterocolitis (NEC), cerebral palsy, length of NICU stay, ventilation care, and parenteral nutrition were significantly greater in the NCU group (microcephaly: $27.7 \%(13 / 47)$ vs. $14.1 \%(29 / 206), P=$ 
0.015; IVH: 53.2\% (25/47) vs. 31.6\% (65/206), $P=0.005$; BPD: 68.1\% (32/47) vs. 30.6\% (63/206), $P<$ 0.001; sepsis: $31.9 \%$ (15/47) vs. $17.0 \%$ (35/206), $P=0.021$; NEC: $17.0 \%$ (8/47) vs. 3.9\% (8/206), $P<0.001$; NICU stay: 90.6 vs. $74.3, P=0.002$; ventilator care: 27.4 vs. $11.9, P<0.001$; parenteral nutrition: 40.6 vs. $25.6, P<0.001)$. Birth weight (BW), rate of low maternal education, and rate of nursery use were significantly lower in the NCU group (BW: $929.9 \mathrm{~g}$ vs. $1084.9 \mathrm{~g}, P<0.001$; low maternal education: $6.4 \%$ (3/47) vs. $19.4 \%(40 / 206), P=0.032$; nursery use: $21.3 \%(10 / 47)$ vs. $37.9 \%(78 / 206), P=0.031)$.

Table 2. Comparison of demographic and perinatal characteristics between the CU and NCU groups of VLBW infants 


\begin{tabular}{|c|c|c|c|}
\hline & $\begin{array}{l}\mathrm{CU} \\
(\mathrm{N}=206)\end{array}$ & $\begin{array}{l}\text { NCU } \\
(\mathrm{N}=47)\end{array}$ & $\begin{array}{l}P \\
\text { value }\end{array}$ \\
\hline GA (wk) & $27.9 \pm 2.0$ & $27.7 \pm 2.1$ & 0.466 \\
\hline BW (g) & $1084.9 \pm 239.1$ & $929.9 \pm 264.4$ & $<0.001^{\star \star \star}$ \\
\hline SGA, n (\%) & $60(29.1)$ & $20(42.6)$ & 0.075 \\
\hline Male sex, n (\%) & $95(46.1)$ & $28(59.6)$ & 0.097 \\
\hline Multiple pregnancy, n(\%) & $72(35.0)$ & $16(34.0)$ & 0.906 \\
\hline Maternal age $(y)$ & $33.0 \pm 4.0$ & $34.2 \pm 3.8$ & 0.052 \\
\hline Cesarean section, n(\%) & $131(63.6)$ & $36(76.6)$ & 0.090 \\
\hline GDM/overt DM, n (\%) & $13(6.3)$ & $6(12.8)$ & 0.131 \\
\hline PIH/chronic HTN, n (\%) & $46(22.3)$ & $10(21.3)$ & 0.876 \\
\hline PROM, n (\%) & $91(44.2)$ & $19(40.4)$ & 0.641 \\
\hline 1-min Apgar score & $4.3 \pm 2.0$ & $3.9 \pm 1.9$ & 0.223 \\
\hline 5-min Apgar score & $6.6 \pm 1.9$ & $6.4 \pm 1.5$ & 0.438 \\
\hline Microcephaly, n (\%) & $29(14.1)$ & $13(27.7)$ & $0.014^{*}$ \\
\hline Neonatal resuscitation, $\mathrm{n}(\%)$ & $185(89.8)$ & $43(91.5)$ & 0.728 \\
\hline Length of stay in NICU (days) & $74.3 \pm 32.1$ & $90.6 \pm 39.4$ & $0.003^{* \star}$ \\
\hline Ventilator care (days) & $11.9 \pm 21.2$ & $27.4 \pm 26.0$ & $<0.001^{\star \star \star}$ \\
\hline Oxygen therapy (days) & $8.8 \pm 10.9$ & $12.9 \pm 14.9$ & $0.032^{*}$ \\
\hline Parenteral nutrition(days) & $25.6 \pm 19.5$ & $40.6 \pm 25.5$ & $<0.001^{\star \star \star}$ \\
\hline RDS, n (\%) & $164(79.6)$ & $38(80.9)$ & 0.849 \\
\hline $\mathrm{IVH}, \mathrm{n}(\%)$ & $65(31.6)$ & $25(53.2)$ & $0.005^{\star \star}$ \\
\hline BPD, n (\%) & $63(30.6)$ & $32(68.1)$ & $<0.001^{\star \star \star}$ \\
\hline PVL, n (\%) & $12(5.8)$ & $6(12.8)$ & 0.096 \\
\hline PDA, n (\%) & $72(35.0)$ & $22(46.8)$ & 0.130 \\
\hline Sepsis, n (\%) & $35(17.0)$ & $15(31.9)$ & $0.020^{*}$ \\
\hline NEC, n (\%) & $8(3.9)$ & $8(17.0)$ & $<0.001^{\star \star \star}$ \\
\hline ROP, n (\%) & $22(10.7)$ & $6(12.8)$ & 0.682 \\
\hline Non parental caregiver, $\mathrm{n}(\%)$ & $7(3.4)$ & $2(4.3)$ & 0.776 \\
\hline
\end{tabular}




\begin{tabular}{llll}
\hline Low maternal education, $\mathrm{n}(\%)$ & $40(19.4)$ & $3(6.4)$ & $0.032^{*}$ \\
\hline Nursery use, $\mathrm{n}(\%)$ & $78(37.9)$ & $10(21.3)$ & $0.031^{*}$ \\
\hline Language therapy, $\mathrm{n}(\%)$ & $6(2.9)$ & $4(8.5)$ & 0.076
\end{tabular}

Abbreviations: BW, Birth weight; BPD, Bronchopulmonary dysplasia; CU, Catch-up group; DM; Diabetes mellitus; GA, Gestational age; GDM, Gestational diabetes mellitus; HTN, Hypertension; IVH, Intraventricular hemorrhage; NCU, No catch-up group; NEC, Necrotizing Enterocolitis; PDA, Patent ductus arteriosus; PIH, Pregnancy induced hypertension; PROM, Premature rupture of membranes; PVL. Periventricular leukomalacia; RDS, Respiratory distress syndrome; ROP, Retinopathy of Prematurity; SGA, Small for gestational age.

${ }^{*} P<0.05$ compared with $\mathrm{CU}$

** $P<0.01$ compared with $\mathrm{CU}$

$\star \star \star ~ P<0.001$ compared with $\mathrm{CU}$

By independent T-test

\section{Correlations between clinical factors and catch-up status of VLBW infants at 18-24 months of CA}

After adjusting for three factors (GA, birth weight, and birth head circumference), only IVH, BPD, sepsis, NEC status, length of ventilator care, and parenteral nutrition were significantly associated with catch-up status. BPD status was the most significant clinical factor affecting catch-up head growth (adjusted OR $4.586,95 \%$ Cl 1.960-10.729) (Table 3).

Table 3. Correlations between clinical factors and catch-up status of VLBW infants at 18-24 months of CA 


\begin{tabular}{|c|c|c|c|c|}
\hline & $\begin{array}{l}\text { OR } \\
(95 \% \mathrm{Cl})\end{array}$ & $\begin{array}{l}P \\
\text { value }\end{array}$ & $\begin{array}{l}\text { aORt } \\
(95 \% \mathrm{Cl})\end{array}$ & $\begin{array}{l}P \\
\text { value }\end{array}$ \\
\hline Length of stay in NICU (days) & $\begin{array}{l}1.012 \\
(1.003-1.022)\end{array}$ & $0.008 * \star$ & $\begin{array}{l}1.011 \\
(0.999-1.024)\end{array}$ & 0.070 \\
\hline Ventilator care (days) & $\begin{array}{l}1.025 \\
(1.012-1.038)\end{array}$ & $<0.001^{\star * \star}$ & $\begin{array}{l}1.028 \\
(1.010-1.046)\end{array}$ & $0.002^{\star \star}$ \\
\hline Oxygen therapy (days) & $\begin{array}{l}1.026 \\
(1.002-1.052)\end{array}$ & $0.037^{*}$ & $\begin{array}{l}1.012 \\
(0.984-1.041)\end{array}$ & 0.398 \\
\hline Parenteral nutrition(days) & $\begin{array}{l}1.029 \\
(1.015-1.044)\end{array}$ & $<0.001^{\star * \star}$ & $\begin{array}{l}1.031 \\
(1.013-1.048)\end{array}$ & $<0.001^{\star \star *}$ \\
\hline $\mathrm{IVH}, \mathrm{n}(\%)$ & $\begin{array}{l}2.465 \\
(1.295-4.693)\end{array}$ & $0.006^{\star *}$ & $\begin{array}{l}2.403 \\
(1.138-5 . .075)\end{array}$ & $0.021^{\star}$ \\
\hline BPD, n (\%) & $\begin{array}{l}4.842 \\
(2.450-9.569)\end{array}$ & $<0.001^{\star \star \star}$ & $\begin{array}{l}4.586 \\
(1.960-10.729)\end{array}$ & $<0.001^{\star \star *}$ \\
\hline Sepsis, n (\%) & $\begin{array}{l}2.290 \\
(1.123-4.672)\end{array}$ & $0.023^{*}$ & $\begin{array}{l}2.380 \\
(1.054-5.371)\end{array}$ & $0.037 *$ \\
\hline NEC, n (\%) & $\begin{array}{l}5.077 \\
(1.797-14.341)\end{array}$ & $0.002^{\star \star}$ & $\begin{array}{l}4.187 \\
(1.207-14.522)\end{array}$ & $0.024^{*}$ \\
\hline
\end{tabular}

Abbreviations: aOR, adjusted odds ratio; BPD, Bronchopulmonary dysplasia; IVH, Intraventricular hemorrhage; NEC, Necrotizing Enterocolitis; OR, Odds ratio.

†Adjusted for Gestational age, Birth weight, and Birth head circumference

$\star P<0.05$

$\star * P<0.01$

$\star * \star P<0.001$

By multiple logistic regression analysis 
Comparison of developmental outcomes between CU and NCU groups of VLBW infants at 18-24 months of CA

At 18-24 months of CA, the NCU group exhibited lower developmental indices and higher rate of developmental delay than the CU group (language developmental index: $92.7 \pm 14.5$ vs. $96.9 \pm 15.3$, $P=0.090$, cognitive developmental index: $91.8 \pm 14.8$ vs. $100.5 \pm 14.3, P<0.001$, motor developmental index: $89.7 \pm 17.5$ vs. $99.1 \pm 12.8, P<0.001$, respectively). Motor developmental delay was the most significantly relevant factor associated with catch-up head growth. The motor development index difference between two groups was only statistically significant after adjusting for four major neonatal morbidities: IVH, BPD, sepsis and NEC status (adjusted OR 10.727, 95\% Cl 1.922-59.868) (Table 4).

Table 4. Comparison of developmental outcomes between CU and NCU groups of VLBW infants at 18-24 months of CA

\begin{tabular}{|c|c|c|c|c|c|c|c|}
\hline & $\begin{array}{l}\mathrm{CU} \\
(\mathrm{N}=206)\end{array}$ & $\begin{array}{l}\text { NCU } \\
(\mathrm{N}=47)\end{array}$ & $\begin{array}{l}P \\
\text { value }\end{array}$ & $\begin{array}{l}\text { OR } \\
(95 \% \\
\mathrm{Cl})\end{array}$ & $\begin{array}{l}P \\
\text { value }\end{array}$ & $\begin{array}{l}\text { aOR } \\
(95 \% \\
\mathrm{Cl})\end{array}$ & $\begin{array}{l}P \\
\text { value }\end{array}$ \\
\hline $\begin{array}{l}\mathrm{LDI}, \mathrm{M} \pm \mathrm{SD} \\
\text { (points) }\end{array}$ & $96.9 \pm 15.3$ & $92.7 \pm 14.5$ & 0.090 & & & & \\
\hline $\begin{array}{l}\text { Developmental } \\
\text { delay, n (\%) }\end{array}$ & $6(2.9)$ & $4(8.5)$ & 0.076 & $\begin{array}{l}3.101 \\
(0.839- \\
11.462)\end{array}$ & 0.986 & $\begin{array}{l}1.364 \\
(0.300- \\
6.195)\end{array}$ & 0.688 \\
\hline $\begin{array}{l}C D I, M \pm S D \\
\text { (points), }\end{array}$ & $100.5 \pm 14.3$ & $91.8 \pm 14.8$ & $<0.001^{\star \star *}$ & & & & \\
\hline $\begin{array}{l}\text { Developmental } \\
\text { delay, } \mathrm{n}(\%)\end{array}$ & $6(2.9)$ & $6(12.8)$ & $0.004 * \star$ & $\begin{array}{l}4.878 \\
(1.498- \\
15.882)\end{array}$ & 0.748 & $\begin{array}{l}2.294 \\
(0.629- \\
8.373)\end{array}$ & 0.209 \\
\hline $\begin{array}{l}\text { MDI, M } \pm \text { SD } \\
\text { (points), }\end{array}$ & $99.1 \pm 12.8$ & $89.7 \pm 17.5$ & $<0.001^{\star \star \star *}$ & & & & \\
\hline $\begin{array}{l}\text { Developmental } \\
\text { delay, } \mathrm{n}(\%)\end{array}$ & $2(1.0)$ & $7(14.9)$ & $<0.001^{\star \star \star}$ & $\begin{array}{l}17.850 \\
(3.577- \\
89.086)\end{array}$ & $0.013^{\star}$ & $\begin{array}{l}10.727 \\
(1.922- \\
59.868)\end{array}$ & $0.007^{\star \star *}$ \\
\hline
\end{tabular}

Abbreviations: CDI, Cognitive developmental index; CU, Catch-up group; NCU, No catch-up group; LDI, Language developmental index; MDI, Motor developmental index; M $\pm S D$, Mean \pm Standard deviations; OR, Odds ratio. 
†Adjusted for IVH, BPD, sepsis and NEC status

* $P<0.05$ compared with CU

** $P<0.01$ compared with CU

*** $P<0.001$ compared with CU

By independent T-test

By multiple logistic regression analysis

\section{Discussion}

This study analyzed 253 VLBW infants with birth weight under 1,500 grams at gestation age of 23 weeks to 31 weeks. Results of this study demonstrated that the degree of head circumference, especially that during 18-24 months of CA, directly affected developmental outcome. Only a small percentage (19.6\%, $47 / 253$ ) of infants exhibited no catch-up head growth at 18-24 months of CA. The developmental outcome depended on the catch-up status at 18-24 months of CA (Table 4).

Head circumference is a valid indicator of total brain volume. It can be used as a proxy for brain growth. Measurement of postnatal head growth as determined by the change in head circumference has been associated with total brain tissue volume and neurodevelopmental outcomes including cognition. It has been reported that severe postnatal growth failure among VLBW infants is markedly influenced by intra uterine growth and major morbidities.

In our study, the key perinatal factor determining catch-up status was the BPD. The pathophysiology that leads to infants with BPD having greater developmental delay is probably multifactorial, including chronic intermittent hypoxia, growth deficiencies, and altered environmental stimulation. First, central nervous system pathology in infants with BPD shows brain atrophy and gliosis compatible with chronic hypoxia ${ }^{6}$. Second, recurrent oxygen desaturations in infants with BPD have been associated with poor weight gain which may give credence to the possibility of poor central nervous system growth $7,8,9,10$. Third, environmental factors such as those associated with rehospitalization during the first year of life and feeding problems might ultimately affect mental development.

In our study, the NCU group exhibited lower developmental indices and higher rate of developmental delay than the CU group at 18-24 month of CA, especially in the motor developmental index. Several studies have documented significant deleterious effects VLBW infants with head growth failure on motor outcome, showing early impairments specifically involving eye-hand coordination and postural balance ${ }^{11,12}$. The impaired control of sensory motor skills might be linked to damage in both the corticospinal tract and visual pathways ${ }^{12}$. Although it is certain that head growth has an impact on the 
developmental outcome of these infants, there are multiple factors that cannot be easily quantified. Whether neonatal morbidities and extra uterine environment with adequate nutritional support have direct or indirect effects on head growth including brain development remains unclear.

Jeug et al. have reported that the severity of BPD has a significantly negative linear relationship with motor developmental outcome in infancy after controlling for other risk factors ${ }^{13}$. Keunen et al. have recently analyzed the complex relationship between nutrition, neonatal morbidities, inflammation, and brain development in VLBW infants and concluded that adequate nutrition is crucial for brain growth and that nutritional therapies and supplements might benefit the developing brain ${ }^{14}$.

VLBW infants might have less prominent, more diffuse cerebral white matter injuries undetectable by ultrasound but can cause developmental disorders. Diffusion-weighted magnetic resonance imaging (MRI) technique provides exquisite soft tissue differentiation. Therefore, a further study is needed to investigate the association of head circumference at 18-24 months of CA with developmental outcome using brain MRI.

The strength of this study was that it included a prospective nationwide population-based cohort of VLBWIs and used a newly revised developmental scale, BSID-III. This is valuable in aspect of analyzing various factors sequentially, including perinatal and postnatal factors. However, this study analyzed only follow-up data at 18-24 month of CA because data regarding long-term follow up of growth pattern and childhood developmental outcomes were unavailable.

In conclusion, developmental level of VLBW infant at 18-24 months of CA depended on whether head growth was caught up. Key clinical factors affecting the catch-up head growth were BPD, NEC status, length of parenteral nutrition, and ventilator care. These results showed the importance of head circumference measurement at 18-24 months of CA. Because infant developmental outcomes can predict school-age academic functioning, our results suggest that close follow-up and early intensive interventions are needed for VLBW infants with catch-up growth failure.

\section{Patients And Methods}

\section{Patients}

Of 8,945 VLBW infants born between January 2014 and November 2017 and registered in the database registry of KNN, 318 with completed Bayley scales of infant and toddler development (BSID) III at 18-24 months of corrected age (CA) were selected for this study. The BSID test was revised and reconstructed into the third edition, which included a separation of the mental developmental index into language scale. We excluded 65 infants due to gestational age (GA) > 32 weeks (42 infants), the presence of major congenital anomalies (8 infants), parents being non-Korean (3 infants), and the presence of post intraventricular hemorrhage (IVH) hydrocephalus (12 infants) (Figure 1). 
Three growth parameters (head circumference, body weight and height) for a specific period of time, including at birth, at discharge from neonatal intensive care unit (NICU), and at 18-24 months of CA, were analyzed. Patients were divided into two groups according to their head circumferences. The first group was the catch-up (CU) group whose head circumference was above the $10^{\text {th }}$ percentile at each measurement period. The second group was the no catch-up (NCU) group whose head circumference was below the $10^{\text {th }}$ percentile at 18-24 month of CA. The cutoff was used because previous researches showed the impact of head growth degree and velocity on neurodevelopmental outcomes ${ }^{15,16,17,18}$.

We compared four major factors: 1) demographic factors (GA, body weight, small for gestational age (SGA), sex, 1-min and 5-min Apgar scores, and microcephaly); 2) maternal factors such as maternal age, cesarean section, and multiple pregnancy, maternal gestational diabetes mellitus (GDM) or overt diabetes mellitus (DM), pregnancy-induced hypertension (PIH) or chronic hypertension (HTN), and premature rupture of membrane (PROM); 3) neonatal morbidity related factors (neonatal resuscitation, length of NICU stay, ventilator care, oxygen therapy, parenteral nutrition, statuses of respiratory distress syndrome (RDS), IVH, bronchopulmonary dysplasia (BPD), periventricular leukomalacia (PVL), patent ductus arteriosus (PDA), neonatal sepsis, necrotizing enterocolitis (NEC), and retinopathy of prematurity (ROP)); and 4) environmental factors (non-parental caregiver, low maternal education, nursery use, and language therapy. All maternal and neonatal variables were compared between the CU and NCU groups at 18-24 months of CA.

\section{Definitions}

We compiled a KNN database operation manual to define patient characteristics. In the manual, GA was determined from the obstetric history based on the last menstrual period. PROM was defined as the rupture of membranes over 24 hours before the onset of labor.

RDS was defined as respiratory distress requiring ventilator care with diagnosis based on chest radiographic findings. IVH was defined as grade $\geq 3$ according to the classification of Papile et al. Post IVH hydrocephalus was defined as IVH-induced hydrocephalus that required spinal tapping, external ventricular drainage, and/or a shunt operation except medical treatment ${ }^{19}$. BPD was defined as the use of more than supplemental oxygen at 36 weeks' gestational age, corresponding to moderate to severe BPD using the severity-based definition for BPD of the National Institutes of Health consensus ${ }^{20}$. PVL was defined as cystic PVL based on either head ultrasound or cranial magnetic resonance imaging scans performed at 2 weeks of age. Symptomatic PDA was defined as clinical symptoms of PDA, such as ventilator dependence, deteriorating respiratory status, increasing recurrent apnea, pulmonary hemorrhage, and hypotension. Early sepsis was defined as a positive blood culture at less than 7 days from birth in symptomatic infants suggestive of septicemia with more than 5 days of antibiotic treatment ${ }^{21}$. NEC was defined as $\geq$ stage $2 \mathrm{~b}$ according to the modified Bell criteria ${ }^{22}$. ROP was defined as any ROP that needed anti-vascular endothelial growth factor and/or laser ablative and/or surgical treatment to prevent visual loss $^{23}$. 
Neonatal resuscitation was defined as the need for initial treatment including oxygen supplementation, positive pressure ventilation, endotracheal intubation, cardiac massage, and any medication. The duration of ventilator care was defined as an endotracheal respiratory support by conventional or high-frequency oscillation ventilation. Oxygen therapy was defined as supplemental support with oxygen via a hood, mask, or low-flow nasal cannula. Low maternal education was defined under high school graduation. Language Composite score $<70$ or Cognitive Composite score $<70$ or Motor Composite score $<70$ was defined as a developmental delay on BSID-III ${ }^{24}$.

\section{Statistical analysis}

Demographic and perinatal characteristics, head circumferences, and language test results were subjected to frequency analysis. Data are described as median (maximum-minimum) for continuous variables and as numbers for binary and categorical variables. Because two independent groups were not normally distributed, the Mann Whitey $\mathrm{U}$ test was used to compare demographic and perinatal characteristics and language developmental results between $\mathrm{CU}$ and NCU groups and to compare clinical characteristics $(P<$ 0.05). Multiple linear regression was employed to determine factors affecting the status of catch-up in head growth. Factors showing statistically significant difference between the two groups were selected and entered into a logistic regression model. When correlation between clinical factor and catch-up status was found, adjusted odds ratio was used to offset the impact of extremely early preterm, small for gestational age, and microcephaly instead of crude odds ratio. These correlations are expressed as odds ratio with $95 \%$ confidence interval $(\mathrm{Cl})$, with a value greater than 1 indicating increased odds of not achieving catch-up after adjusting for GA, birth weight, and birth head circumference. When comparing developmental outcomes between the two groups, the adjusted odds ratio was used after adjusting four major neonatal morbidities: IVH, BPD, sepsis, and NEC status. A $P$-value $<0.05$ was considered to indicate statistical significance. All statistical analyses were performed using SPSS software ver. 26.0 (IBM Corp., Chicago, IL, USA).

\section{Declarations}

\section{Ethics statement}

The KNN registry was approved by the Institutional Review Board (IRB) at each participating hospital. Informed consent was obtained from parents at enrollment by the NICU participating in the KNN. Informed consent was waived by the IRB for infants who died in the delivery room or at the early stage in the NICU before informed consent was able to be obtained for chart review. Trained staff used a standardized operating procedure to collect demographic and clinical information. The present study was performed in accordance with the ethical standards as laid down in the 1964 Declaration of Helsinki and its later amendments. De-identified KNN data were approved by the Institutional Review Board (IRB) of Jeonbuk National University Hospital for further analysis and interpretation.

\section{Data Availability}


Data availability was subject to the Act on Bioethics and Safety [Law No. 1518, article 18 (Provision of Personal Information)]. Contact for sharing the data or accessing the data is possible only through the data committee of Korean neonatal network (http://knn.or.kr) and after permission by the CDC of Korea. Please contact Yun Sil Chang (cys.chang@samsung.com) for data access and and Jang Hoon Lee (neopedlee@gmail.com) for ethics committees.

\section{Acknowledgements}

This paper was supported by Fund of Biomedical Research Institute, Jeonbuk National University Hospital.

\section{Author Contributions}

JKK conceptualized and designed the study and reviewed and revised the manuscript. DHC and YMH designed the data collection instruments, collected data, carried out the initial analyses, and drafted the initial manuscript. All authors approved the final manuscript as submitted and agree to be accountable for all aspects of the work.

Financial Disclosure: The authors have no financial relationships relevant to this article to disclose.

Competing Interests: The authors declare no competing interests.

\section{References}

1. Hahn, W.-H., Chang, J.-Y., Chang, Y. S., Shim, K. S. \& Bae, C.-W. Recent Trends in Neonatal Mortality in Very Low Birth Weight Korean Infants: In Comparison with Japan and the USA. J. Korean Med. Sci. 26, 467 (2011).

2. Cooke, R. W. I. Growth impairment in the very preterm and cognitive and motor performance at 7 years. Arch. Dis. Child. 88, 482-487 (2003).

3. Peterson, J., Taylor, H. G., Minich, N., Klein, N. \& Hack, M. Subnormal head circumference in very low birth weight children: Neonatal correlates and school-age consequences. Early Hum. Dev. 82, 325334 (2006).

4. Takeuchi, A. et al. Catch-up growth and behavioral development among preterm, small-forgestational-age children: A nationwide Japanese population-based study. Brain Dev. 41, 397-405 (2019).

5. Linsell L., Malouf R., Morris J., Jennifer J. K., Marlow N. Prognostic factors for poor cognitive development in children born very preterm or with very low birth weight: a systematic review. JAMA Pediatr. 169, 1162-1172 (2015).

6. Samuel J. M., James W. P., Dietrich W. R., Patricia L. P., Gilbert S. S. Growth and Development of Preterm Infants with Respiratory Distress Syndrome and Bronchopulmonary Dysplasia. Pediatrics. 77, 345-352 (1986). 
7. Kurzner, I., Bautista, D. B. \& Keens, G. Clinically Unsuspected Hypoxia during Sleep and Feeding in Infants With Bronchopulmonary Dysplasia. 10. Pediatrcs. 81, 635-642 (1988).

8. Sekar K. C., James C. D. Sleep Apnea and Hypoxemia in Recently Weaned Premature Infants with and without Bronchopulmonary Dysplasia. Pediatric Pulmol. 10, 112-116 (1991).

9. Tay-Uyboco, J. S., Kwiatkowski, K., Cates, D. B., Kavanagh, L. \& Rigatto, H. Hypoxic airway constriction in infants of very low birth weight recovering from moderate to severe bronchopulmonary dysplasia. J. Pediatr. 115, 456-459 (1989).

10. Singer, L. et al. Oxygen Desaturation Complicates Feeding in Infants With Bronchopulmonary Dysplasia After Discharge. Pediatrics. 90, 380-384 (1992).

11. Katz-Salamon, M. Early motor and mental development in very preterm infants with chronic lung disease. Arch. Dis. Child. - Fetal Neonatal Ed. 83, 1F - 6 (2000).

12. Skranes J. S., Vik T., Nilsen G., Smevik G., Andersson H. W., Brubakk A. M. Cerebral Magnetic Resonance Imaging and Mental and Motor Function of Very Low Birth Weight Children at Six Years of Age. Neuropediatrics. 28, 149-154 (1997).

13. Jeng, S.-F. et al. Bronchopulmonary dysplasia predicts adverse developmental and clinical outcomes in very-low-birthweight infants. Dev. Med. Child Neurol. 50, 51-57 (2008).

14. Keunen, K., van Elburg, R. M., van Bel, F. \& Benders, M. J. N. L. Impact of nutrition on brain development and its neuroprotective implications following preterm birth. Pediatr. Res. 77, 148-155 (2015).

15. Frisk, V., Amsel, R. \& Whyte, H. E. A. The Importance of Head Growth Patterns in Predicting the Cognitive Abilities and Literacy Skills of Small-for-Gestational-Age Children. Dev. Neuropsychol. 22, 565-593 (2002).

16. Raz, S., Newman, J. B., DeBastos, A. K., Peters, B. N. \& Batton, D. G. Postnatal growth and neuropsychological performance in preterm-birth preschoolers. Neuropsychology 28, 188-201 (2014).

17. Brandt, I., Sticker, E. J. \& Lentze, M. J. Catch-up growth of head circumference of very low birth weight, small for gestational age preterm infants and mental development to adulthood. J. Pediatr. 142, 463470 (2003).

18. Latal-Hajnal, B., Von Siebenthal, K., Kovari, H., Bucher, H. U. \& Largo, R. H. Postnatal growth in VLBW infants: significant association with neurodevelopmental outcome. J. Pediatr. 143, 163-170 (2003).

19. Papile, L.-A., Burstein, J., Burstein, R. \& Koffler, H. Incidence and evolution of subependymal and intraventricular hemorrhage: A study of infants with birth weights less than 1,500 gm. J. Pediatr. 92, 529-534 (1978).

20. Jobe, A. H. \& Bancalari, E. Bronchopulmonary Dysplasia. 163, 7 (2001).

21. Park, J. H., Chang, Y. S., Sung, S. \& Park, W. S. Mortality Rate-Dependent Variations in the Timing and Causes of Death in Extremely Preterm Infants Born at 23-24 Weeks' Gestation*: Pediatr. Crit. Care Med. 20, 630-637 (2019).

22. Bell, M. J. \& Marshall, R. Neonatal Necrotizing Enterocolitis. 7. 
23. The International Classification of Retinopathy of Prematurity Revisited. Arch. Ophthalmol. 123, 991 (2005).

24. Sharp, M. \& DeMauro, S. B. Counterbalanced Comparison of the BSID-II and Bayley-III at Eighteen to Twenty-two Months Corrected Age. J. Dev. Behav. Pediatr. 38, 322-329 (2017).

\section{Figures}
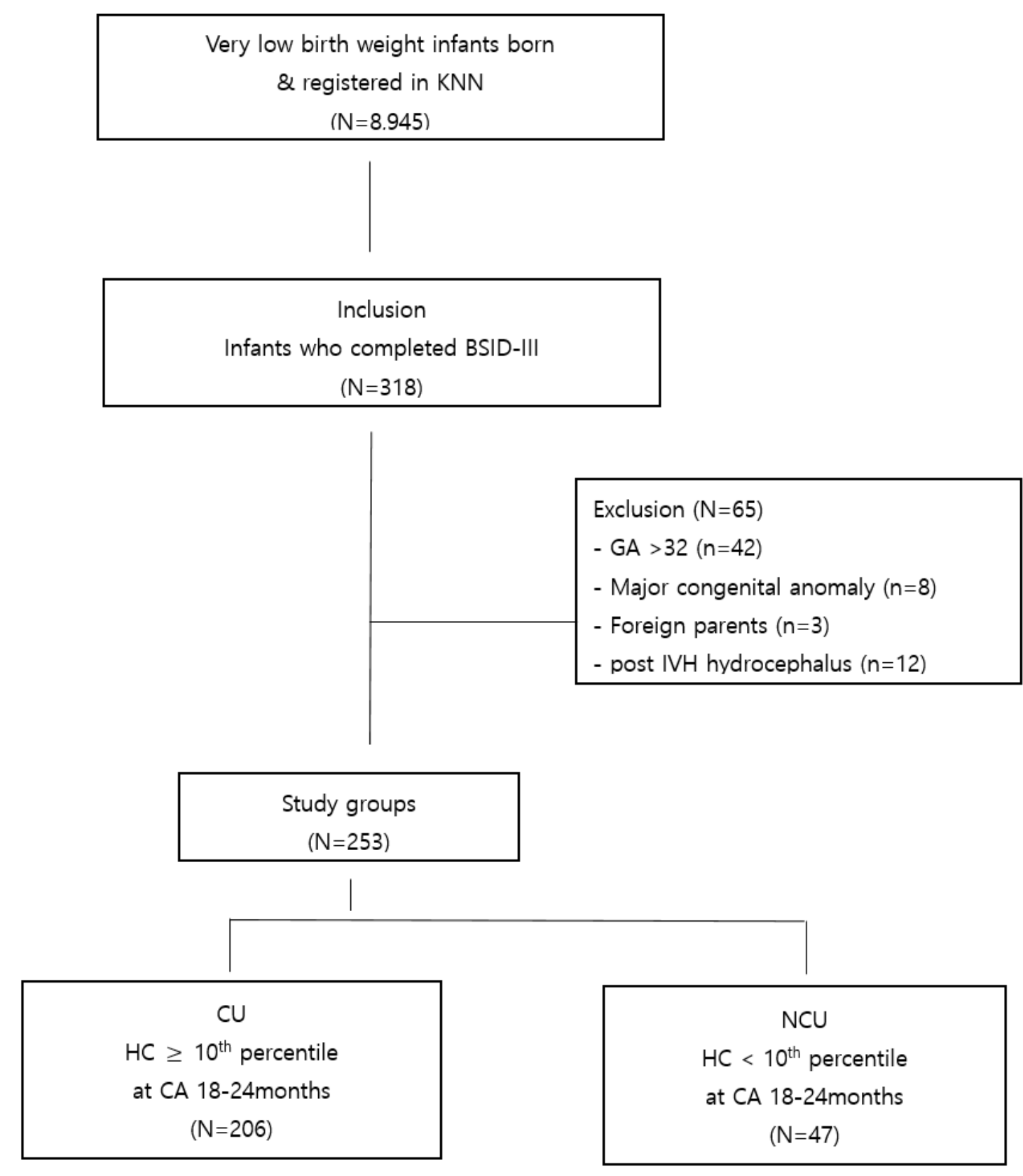

Abbreviations: BSID, Bayley Scales of Infant and Toddler Development; CU, Catch-up group; GA, Gestational age; HC, Head circumference; KNN, Korean Neonatal Network; NCU, No catch-up group. 
Figure 1

Flowchart outlining the selection of the study population. This study enrolled 318 VLBWls. After excluding 65 infants, the remaining infants $(n=253)$ who had completed Bayley scales of infant and toddler development (BSID) 3rd were assigned into two groups: a catch-up (CU) group with head circumference above the 10th percentile and a no catch-up (NCU) group with head circumference below the 10th percentile at 18-24 months of corrected age (CA).

\section{Supplementary Files}

This is a list of supplementary files associated with this preprint. Click to download.

- Appendix1.docx 